\title{
Investigation of the fractal dimension of rainfall occurrence in a semi-arid Mediterranean climate
}

\author{
H. Ghanmi , Z. Bargaoui \& C. Mallet
}

To cite this article: H. Ghanmi , Z. Bargaoui \& C. Mallet (2013) Investigation of the fractal dimension of rainfall occurrence in a semi-arid Mediterranean climate, Hydrological Sciences Journal, 58:3, 483-497, DOI: 10.1080/02626667.2013.775446

To link to this article: https://doi.org/10.1080/02626667.2013.775446

曲 Published online: 08 Mar 2013.

Submit your article to this journal $\widetilde{ }$

Џll Article views: 614

Q View related articles $₫$

4 Citing articles: 8 View citing articles 


\title{
Investigation of the fractal dimension of rainfall occurrence in a semi-arid Mediterranean climate
}

\author{
H. Ghanmi ${ }^{1,2}$, Z. Bargaoui ${ }^{1}$ and C. Mallet ${ }^{2}$ \\ ${ }^{I}$ Laboratory of Modelling in Hydraulics and Environment (LMHE), National Engineering School of Tunis (ENIT), University of Tunis El \\ Manar (UTM), BP 37, Tunis Belvedere 1002, Tunisia \\ hanen.ghanmi@gmail.com; zoubeida.bargaoui@laposte.net \\ ${ }^{2}$ Laboratoire Atmosphères, Milieux, Observations Spatiales (LATMOS), University of Versailles Saint-Quentin-en-Yvelines, CNRS/INSU, \\ 11 Boulevard d'Alembert, 78280 Guyancourt, France \\ cecile.mallet@1atmos.ipsl.fr
}

Received 6 January 2012; accepted 2 October 2012; open for discussion until 1 October 2013

Editor Z.W. Kundzewicz; Associate editor S. Grimaldi

Citation Ghanmi, H., Bargaoui, Z., and Mallet, C., 2013. Investigation of the fractal dimension of rainfall occurrence in a semi-arid Mediterranean climate. Hydrological Sciences Journal, 58 (3), 483-497.

\begin{abstract}
The scale invariance of rainfall series in the Tunis area, Tunisia (semi-arid Mediterranean climate) is studied in a mono-fractal framework by applying the box counting method to four series of observations, each about 2.5 years in length, based on a time resolution of $5 \mathrm{~min}$. In addition, a single series of daily rainfall records for the period 1873-2009 was analysed. Three self-similar structures were identified: micro-scale (5 min to 2 d) with fractal dimension 0.44 , meso-scale ( $2 \mathrm{~d}$ to one week) and synoptic-scale (one week to eight months) with fractal dimension 0.9. Interpretation of these findings suggests that only the micro-scale and transition to saturation are consistent, while the high fractal dimension relating to the synoptic scale might be affected by the tendency to saturation. A sensitivity analysis of the estimated fractal dimension was performed using daily rainfall data by varying the series length, as well as the intensity threshold for the detection of rain.
\end{abstract}

Key words semi-arid Mediterranean climate; fractal dimension; rainfall time series; scale-invariance; on-off intermittency; mono-fractal; box counting

Etude de la dimension fractale d'occurrence de pluie dans un climat méditerranéen semi-aride Résumé La loi d'invariance d'échelle de l'occurrence de pluie dans un climat semi-aride a été étudiée dans le cadre d'une analyse fractale. La dimension fractale du support est estimée en appliquant la méthode de comptage de boîtes. Des séries d'observations, issues de quatre stations de la région de Tunis (Tunisie), de résolution 5 min pendant la période 2007-2010, ainsi qu'une série de résolution journalière de plus de 100 ans (1873-2009) ont été analysées. Ainsi, trois structures auto-similaires ont été identifiés: les micro-échelles ( 5 min à $2 \mathrm{j}$ ) ayant une dimension fractale de 0,44 , les méso-échelles ( $2 \mathrm{j}$ à une semaine) et l'échelle synoptique (une semaine à huit mois) ayant une dimension fractale de 0,9 . L'interprétation de ces résultats suggère que seules les micro-échelles et la transition vers la saturation sont significatives, tandis que la dimension fractale assez élevée relative à l'échelle synoptique pourrait être affectée par la tendance à la saturation. Une étude de sensibilité de la dimension fractale de l'occurrence de pluie utilisant la série de précipitations journalières a été effectuée en faisant varier la longueur de la série ainsi que le seuil de détection de la pluie.

Mots clefs climat méditerranéen semi-aride; dimension fractale; séries chronologiques de pluie; invariance d'échelle; intermittence; mono-fractal; méthode de comptage de boîtes

\section{INTRODUCTION}

Rainfall is a process that generally shows high spatial and temporal variability. This variability is controlled mainly by intermittence (occurrence - non-occurrence). In the case of rainfall time series, the rainfall support is a set of disjointed rainfall periods scattered on the time axis. This support can be considered as a fractal object (it presents properties of invariance by focus) and is characterized 
by a non-integer "fractal dimension" (Mandelbrot 1975, 1982). This dimension is interpreted as the degree of irregularity according to which the support is distributed. The first empirical results proving the existence of properties of scale invariance for rainfall were established in a mono-fractal framework (Lovejoy 1981, 1982).

There are various fractal dimension estimation methods. The method of box counting is the oldest and the most frequently used. According to Falconer (1990), its definition goes back to the 1930 s, at least. It has been referred to by different terms, namely Kolmogorov's entropy or capacity, the entropy dimension, the capacity dimension, the metrics of dimension, the logarithmic density and the information dimension. The evaluation of fractal dimension of rainfall occurrence allows the interference of a rainfall threshold to qualify the rain support corresponding to different rainfall intensities (Hubert and Carbonnel 1989, Olsson et al. 1992). By changing the value of the threshold, it seems that the fractal dimension varies (Friggit et al. 1991, Olsson et al. 1992, 1993, Hubert 1995, Hubert et al. 1995). In particular, Olsson et al. (1992, 1993) provided evidence of the existence of many rain regimes, each of them characterized by scale invariance. Thus, the monofractal assumption has been extended to multi-fractal models in the framework of which the rainfall process is characterized by a hierarchy of fractals leading to a multi-fractal or multi-scale process (Biaou 2004). Schertzer and Lovejoy (1987, 2006), Gupta and Waymire (1993), Tessier et al. (1993) and Schertzer et al. (2006) developed a universal model (multi-fractal), as well as different methods of identification of its parameters. In addition, the fractal and/or multi-fractal characterization of rain intensity has been adopted for the elaboration of intensity-duration-frequency (IDF) curves (Bendjoudi et al. 1997, Menabde et al. 1999, De Michele et al. 2002, 2011, Castro et al. 2004, Langousis and Veneziano 2006, Bara et al. 2009, Langousis et al. 2009).

In this paper, we investigate rainfall occurrence by studying the fractal dimension of the support of precipitation and its properties of scale invariance. Recent work (de Montéra et al. 2009, Verrier et al. 2010,2011) analysed the influence of rainfall zeros on multi-fractal analysis. A bias was noted in the estimation of parameters of the multi-fractal model on intermittent series, as well as the appearance of breaks on the scaling separating various regimes. An in-depth study of the fractal dimension of precipitation support and the regions of scale invariance is considered an indispensable preamble to the multifractal analysis.

According to the literature review, there are no such studies dealing with rainfall occurrence in the semi-arid Mediterranean climate. Hubert and Carbonnel (1989) and Friggit et al. (1991) have studied the fractal dimension of rainfall occurrence in the Sudano-Sahelien transition zone between the Sahel and the Sudan-Guinea region (M'Biandoun et al. 2002). This area is characterized by two seasons: a rainy one and a dry one, and average annual rainfall is 600-900 mm (PANA 2003). Olsson et al. (1992, 1993) studied a Swedish region (Lund) characterized by an oceanic climate of a cold winter $(-1 \leq T \leq$ $\left.3^{\circ} \mathrm{C}\right)$ and a hot summer $\left(13 \leq T \leq 20^{\circ} \mathrm{C}\right)$. In the same context, Verrier et al. (2011) worked in the Palaiseau region (France) that has an oceanic climate of mild rainy winters and fresh and relatively damp summers; maximum rainfall occurs during the cold season and average annual rainfall is $600 \mathrm{~mm}_{\text {year }}{ }^{-1}$. Table 1 summarizes the information from previous studies: the length and resolution of rainfall time series, zones of scale invariance and fractal dimension, $D_{f}$. The differences which appear in Table 1 may be due to the diversity of the regions concerned and of the measurement devices used (totalizer raingauges, tipping-bucket gauges and disdrometers), and also of the rainfall threshold adopted and the time resolutions.

This study examines pluviographic and pluviometric information for the Tunis area, which has a semi-arid Mediterranean climate. Time series from four automatic raingauges that represent an area of $265 \mathrm{~km}^{2}$, and have collected data since 2008, are first examined. Rainfall values are recorded every $5 \mathrm{~min}$ and sent by radio to the control centre. In addition, a series of daily rainfall observations from a single station was studied; observations are nominally made at 07:00 h local time and record the total precipitation for the preceding $24 \mathrm{~h}$. These daily observations are available since 1873 . The study area has variable annual rainfall amounts and the rainfall is unevenly distributed by season. Indeed autumn-winter rainfall represents $71 \%$ of the annual rainfall, the remainder occurring in spring-summer (Isnard 1952). These data are presented in Section 2.

The methodology applied is described and the box-counting approach is reviewed briefly in Section 3. Sections 4 and 5 present the analysis of the rain support obtained for the 5-min and daily series. Section 6 considers the evolution of the fractal dimension of rain occurrence over the 20th 
Table 1 Observed fractal dimensions, $D_{f}$, reported in previous studies at zero detection threshold.

\begin{tabular}{|c|c|c|c|}
\hline Reference & Measurement & Range of scale & $D_{f}$ \\
\hline Tessier et al. $(1988,1989)$ & $\begin{array}{l}3 \text { years of daily accumulations ( } 8000 \text { stations in OMM } \\
\text { network) }\end{array}$ & $\begin{array}{l}1 \mathrm{~d}-8 \text { months } \\
8 \text { months }-1 \text { year }\end{array}$ & $\begin{array}{l}0.80 \\
1\end{array}$ \\
\hline Hubert and Carbonnel (1989) & $\begin{array}{l}45 \text { years of daily records (Station of Dedougou, Burkina } \\
\text { Faso) } \\
170 \text { d of hourly records (Station of Ouagadougou, Burkina } \\
\text { Faso) }\end{array}$ & $\begin{array}{l}8 \mathrm{~d}-4 \text { months } \\
8 \mathrm{months}-45 \text { years } \\
4 \mathrm{~h}-32 \mathrm{~h} \\
64 \mathrm{~h}-10.66 \mathrm{~d} \\
21.33 \mathrm{~d}-170 \mathrm{~d}\end{array}$ & $\begin{array}{l}0.79 \\
1 \\
0.22 \\
0.74 \\
1\end{array}$ \\
\hline Olsson et al. (1992) & $\begin{array}{l}2 \text { years of observations. Resolution }=\text { minutes (Lund, } \\
\text { Sweden) }\end{array}$ & $\begin{array}{l}1-45 \min \\
45 \text { min }-7 \mathrm{~d} \\
7 \mathrm{~d}-2 \text { years }\end{array}$ & $\begin{array}{l}0.78 \\
0.35 \\
1\end{array}$ \\
\hline & 90 years of daily observations (Lund, Sweden) & $\begin{array}{l}1-10 \mathrm{~d} \\
10 \mathrm{~d}-90 \text { years }\end{array}$ & $\begin{array}{l}0.59 \\
1\end{array}$ \\
\hline & 170 years of monthly observations (Lund, Sweden) & 1 month -170 years & 1.00 \\
\hline Olsson et al. (1993) & $\begin{array}{l}2 \text { years of observations. Resolution = minutes (Lund, } \\
\text { Sweden) }\end{array}$ & $\begin{array}{l}1-45 \text { min } \\
45 \text { min }-7 \mathrm{~d} \\
7 \mathrm{~d}-2 \text { years }\end{array}$ & $\begin{array}{l}0.82 \\
0.37 \\
1\end{array}$ \\
\hline Lavergnat and Golé (1998) & 4 months of data. Resolution $=1 \mathrm{~ms}$ (Ile de France, France) & $\begin{array}{l}10 \mathrm{~ms}-7 \mathrm{~d} \\
7 \mathrm{~d}-4 \text { months }\end{array}$ & $\begin{array}{l}0.82 \\
1\end{array}$ \\
\hline Schmitt et al. (1998) & 28 years of rainfall. Resolution $=10 \mathrm{~min}($ Uccle, Belgium $)$ & $\begin{array}{l}10 \min -3.5 \mathrm{~d} \\
3.5 \mathrm{~d}-70 \mathrm{~d}\end{array}$ & $\begin{array}{l}0.55 \\
1\end{array}$ \\
\hline Veneziano and Iacobellis (2002) & 24 years of rainfall. Resolution $=20 \mathrm{~min}$ (Florence, Italy) & $20 \min -3.5 \mathrm{~d}$ & 0.50 \\
\hline Verrier et al. (2011) & $\begin{array}{l}2 \text { years of measurements Resolution }=15 \mathrm{~s} \text { (disdrometer) } \\
(\text { Palaiseau, France })\end{array}$ & $30 \mathrm{~min}-1.5 \mathrm{~d}$ & 0.55 \\
\hline De Lima and de Lima (2009) & $\begin{array}{l}49 \text { years of daily observations. (Madeira, Portugal) } \\
4 \text { months of data. Resolution }=10 \text { min (Madeira, Portugal) }\end{array}$ & $\begin{array}{l}1-16 \mathrm{~d} \\
10 \mathrm{~min}-3.6 \mathrm{~d}\end{array}$ & $\begin{array}{l}0.56 \\
0.56\end{array}$ \\
\hline
\end{tabular}

century; and concluding remarks are presented in Section 7.

\section{BRIEF DESCRIPTION OF THE TUNIS REGION RAINFALL}

The data used for this study come from the database of the General Directorate of Water Resources (Direction Générale des Ressources en Eau, DGRE) of the Ministry of Agriculture, Tunisia. The stations are (Fig. 1): Tunis-Manoubia, Mornag, Soukra and Sidi Thabet.

The four stations are located in the zone which is under marine influence. Here we use the available rainfall time series to ensure the representativeness of the results obtained. These data come from automatic raingauges and tipping-bucket raingauges. The smallest recorded height of water in the four 5-min resolution series is $0.024 \mathrm{~mm}$. The series lengths vary between one and 2.5 years (Table 2). For the Tunis-Manoubia station, one of the oldest stations in Tunisia, we also obtained the 136-year daily series measured by the totalizer raingauge. The measurement is recorded daily at 07:00 h. The smallest height of water recorded at daily resolution is $0.9 \mathrm{~mm}$. Table 2 summarizes the station details: coordinates (latitude, longitude), elevation, and start and end dates of the series.

In the following, we evaluate the main statistics of the 5-min series for the four stations, and also the daily, monthly and yearly scale for the TunisManoubia station.

\subsection{Study of rainfall variability at time periods of 5 min}

A preliminary study, which will be useful for the later interpretation, was performed on the 5-min time series. In Table 3, we show the maximum possible length squared of the 5-min time series for each station (squared for use in the box-counting method); the percentage of rain absence ( $\%$ of zero records); the number, average and maximum duration of rainfall events, the duration of events cumulated in days; and the average and maximum duration of rainless periods for each series. A rainfall event is defined as any period of rainfall located between two non-rainy periods.

We note the good coherence of rainfall between the stations, except for Soukra, for which the series is only one half as long and presents a much smaller cumulated duration of events and lower number of 


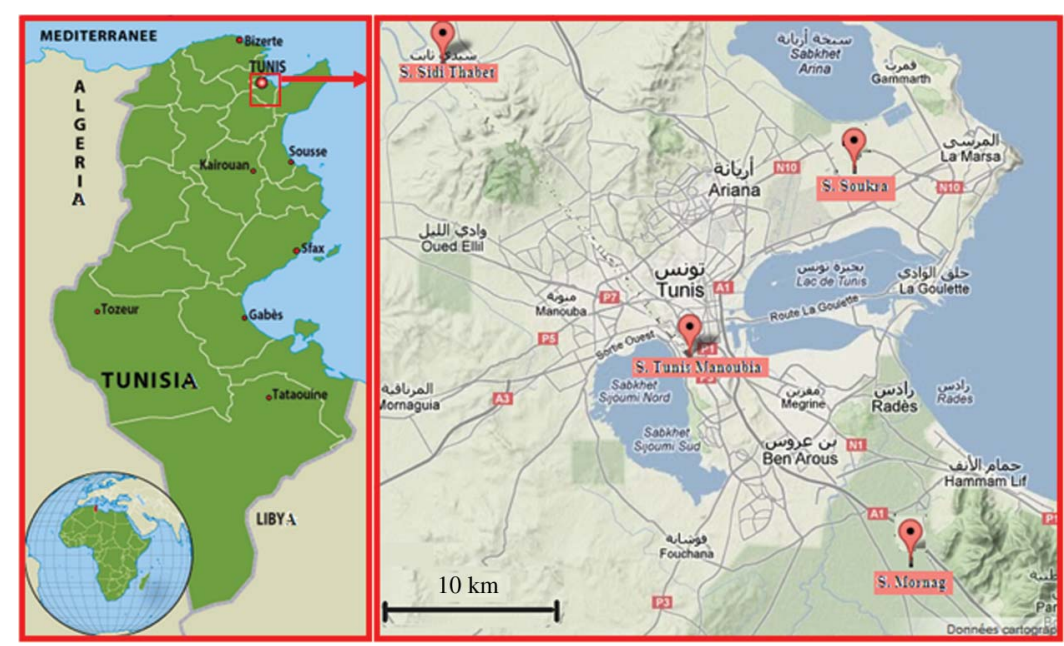

Fig. 1 Location of the four gauging stations (left: http://www.rfi.fr/actufr/articles/118/article_85956.asp; right http://www. distancity.com/en/).

Table 2 Available data sets of the stations studied.

\begin{tabular}{lllllll}
\hline Station & Long. & Lat. & Alt. $(\mathrm{m})$ & Start & End & Resolution \\
\hline Tunis-Manoubia & $8^{\circ}, 7060$ & $40^{\circ}, 8711$ & 66 & $31 / 12 / 2007$ & $05 / 08 / 2010$ & $5 \mathrm{~min}$ \\
Mornag & $8^{\circ}, 8500$ & $40^{\circ}, 6600$ & 35 & $31 / 12 / 2007$ & $31 / 07 / 2010$ & $5 \mathrm{~min}$ \\
Sidi Thabet & $8^{\circ}, 5580$ & $41^{\circ}, 0040$ & 20 & $31 / 08 / 2007$ & $14 / 05 / 2010$ & $5 \mathrm{~min}$ \\
Soukra & $8^{\circ}, 3770$ & $40^{\circ}, 9540$ & 15 & $31 / 12 / 2007$ & $23 / 05 / 2010$ & $5 \mathrm{~min}$ \\
Tunis-Manoubia & $8^{\circ}, 7060$ & $40^{\circ}, 8711$ & 66 & $31 / 12 / 1872$ & $31 / 08 / 2009$ & $1 \mathrm{~d}$ \\
\hline
\end{tabular}

Table 3 Characteristics of time series of 5-min resolution for the four Tunis stations.

\begin{tabular}{lllll}
\hline & Tunis-Manoubia & Mornag & Soukra & Sidi Thabet \\
\hline Start date & $31 / 12 / 2007,07: 00$ & $31 / 12 / 2007,07: 00$ & $31 / 12 / 2007,07: 00$ & $31 / 08 / 2007,07: 00$ \\
End date & $28 / 06 / 2010,09: 50$ & $28 / 06 / 2010,09: 50$ & $30 / 03 / 2009,09: 25$ & $26 / 02 / 2010,10: 50$ \\
Length of series (min) & $5 \times 2^{18}$ & $5 \times 2^{18}$ & $5 \times 2^{17}$ & $5 \times 2^{18}$ \\
\% of zero & 99.2 & 99.0 & 99.3 & 99.0 \\
Number of events in the series & 1092 & 1298 & 480 & 1508 \\
Cumulative duration of events (d) & 7.5 & 9.1 & 3.0 & 8.8 \\
Average duration of events (min) & 9.9 & 10.1 & 25.1 & 220 \\
Maximum duration of events (min) & 195 & 235 & 14 & 20 \\
Average length of dry periods (h) & 19 & 88 & 124 & 117 \\
Max duration of dry period (d) & 74 & & & \\
\hline
\end{tabular}

events. Generalizing, the four stations are dry with a percentage of zeros $\geq 99 \%$. The average duration of rainfall events is $8-10 \mathrm{~min}$ and the minimum duration is $5 \mathrm{~min}$ (the series time step). The longest rainfall event was observed at Soukra, on 31 March 2008, lasting $4 \mathrm{~h} 15 \mathrm{~min}$ (starting at 20:25 h). The statistical distribution of event duration is extremely asymmetrical. The first quartile and the median are superposed and equal to $5 \mathrm{~min}$, meaning that more than half of the events correspond to one isolated observed nonnull data. The third quartile equals $10 \mathrm{~min}$ for both Tunis-Manoubia and Mornag (situated in the south of the study zone). It falls between 5 and 10 min for Sidi Thabet and Soukra (in the north). The shortness of the cumulated durations relative to the series' durations provides an idea of the scarcity of rainfall.

\subsection{Study of the variable character of daily, monthly and yearly rainfall}

In this section, we refer only to the Tunis-Manoubia daily rainfall series, and the monthly evolution of the number of rain days and the standard deviations for the period between the 1 January 1879 and 31 December 2008 (Fig. 2). 

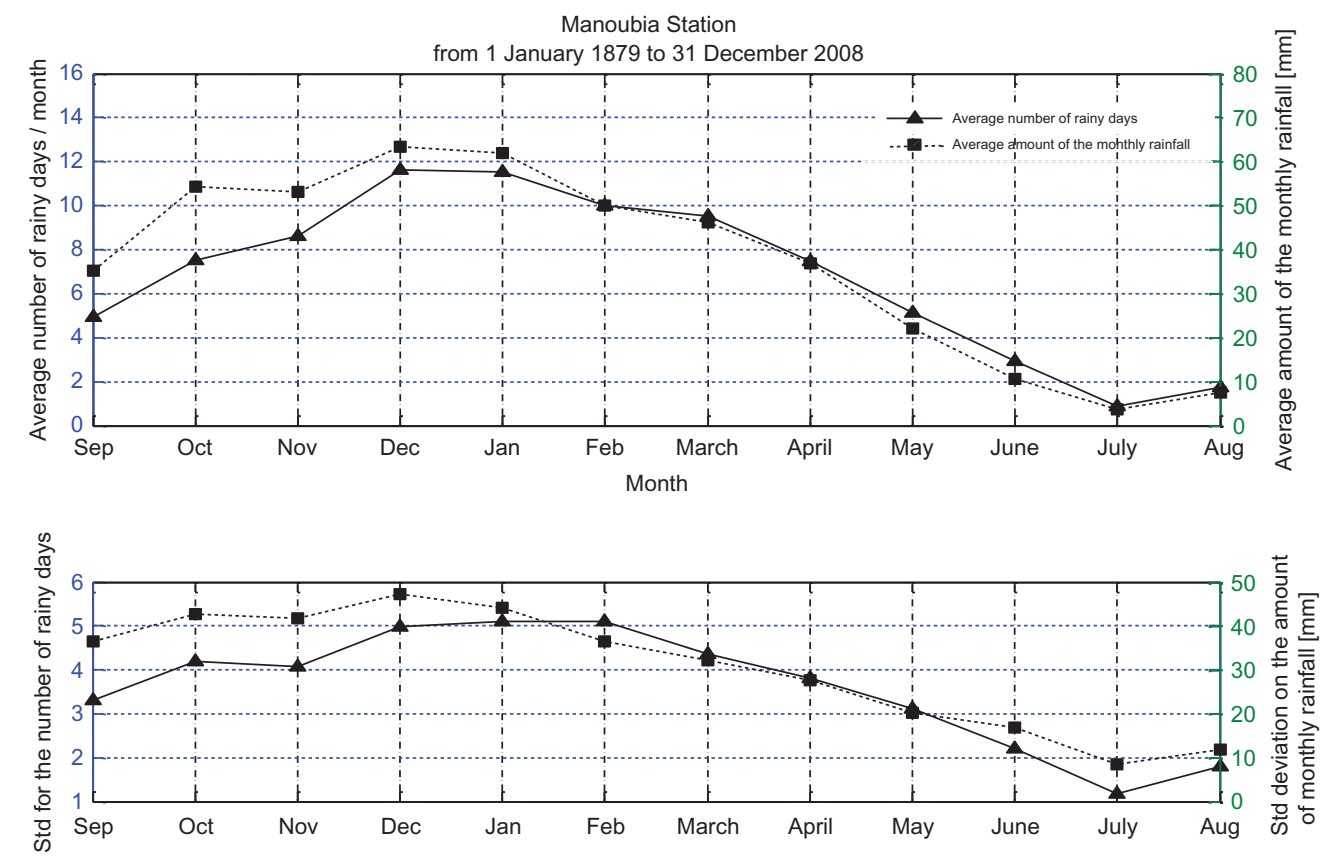

Fig. 2 Average monthly rainfall ( $(\mathbf{})$ and mean monthly number of rain days per month ( $\mathbf{\Delta}$ ) during the period from 1 January 1879 to 31 December 2008 (top: mean values; bottom: standard deviation).

In Fig. 2, the rainfall is concentrated mainly between the months of September and May on a limited number of days. Rainfall is almost absent during the summer (June, July and August). There is a pronounced maximum in December and a minimum in July. These results were compared to those of Isnard $(1950,1952)$ for Algeria and Tunisia. The large interannual variability is similar and represented by the coefficients of variation (ratio of standard deviation to the mean) that range from 0.7 for March to 2.3 for July for monthly rainfall amount, and between 0.5 (December) and 1.3 (July) for the monthly number of rainy days.

Figure 3 shows the annual rainfall and number of rainy days for 1 September 1873 to 31 August 2008. The annual rainfall series (Fig. 3) highlights an important inter-annual variability of rainfall. The cumulative average annual rainfall over this period is equal to $444 \mathrm{~mm}$ with a standard deviation of $126 \mathrm{~mm}$. The annual average number of rain days is $79 \mathrm{~d}$ and the standard deviation is $27 \mathrm{~d}$. Extremely dry years (relative to the average) as well as very humid ones occur. The minimum annual amount reported was for $1879 / 80,143 \mathrm{~mm}$. However, as discussed below, we challenge the quality of the data collected before 1900. Nevertheless, we note that extremely low annual values $(\sim 200 \mathrm{~mm})$ have been observed throughout the series with a minimum rainfall amount of $210 \mathrm{~mm}$ recorded in $2001 / 02$. The annual maximum of $808 \mathrm{~mm}$ was recorded in 1958/59 and more recently a maximum of $794 \mathrm{~mm}$ was recorded in 2003/04. Analysis using calendar years, rather than hydrological years as presented in Fig. 3, gives similar results. Non-parametric estimation of the density distribution of rain days and annual precipitation totals was performed using kernel density estimation (Silverman 1998). With a Gaussian kernel, we obtain the kernels represented in Fig. 4(a) and (b).

For the daily series from 1 September 1873 to 31 August 2008, the density of the distribution of rain days presents two sub-populations (Fig. 4(a), dashed line). The first sub-population corresponds to years with a mode value around $88 \mathrm{~d} /$ year. The second subpopulation, composed only of 7 years (Table 4), has a mode of $9 \mathrm{~d} /$ year; these years are listed in Table 4 with their corresponding rainfalls.

We note that all the years making up this subpopulation are before 1900, which puts in doubt the quality of the data recorded before that date. When the data of the period before 1900 are omitted, a unimodal density of rain days is obtained (Fig. 4(a), solid line). Concerning the distribution of the density of the annual amount of precipitation (Fig. 4(b)), we do not see any specific behaviour for the series including the years before 1900. Both density distributions are unimodal. This yields two hypotheses: either, for 


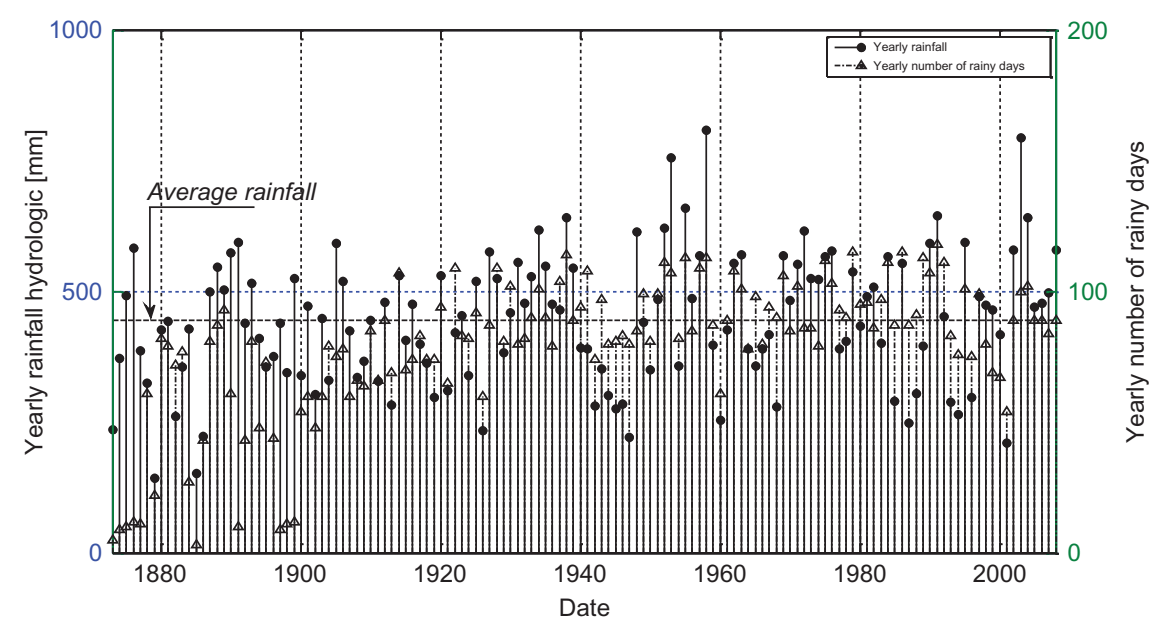

Fig. 3 Yearly rainfall (•) and number of rainy days (\$) from 1 September 1873 to 31 August 2008; hydrological years starting on 1 September are considered.
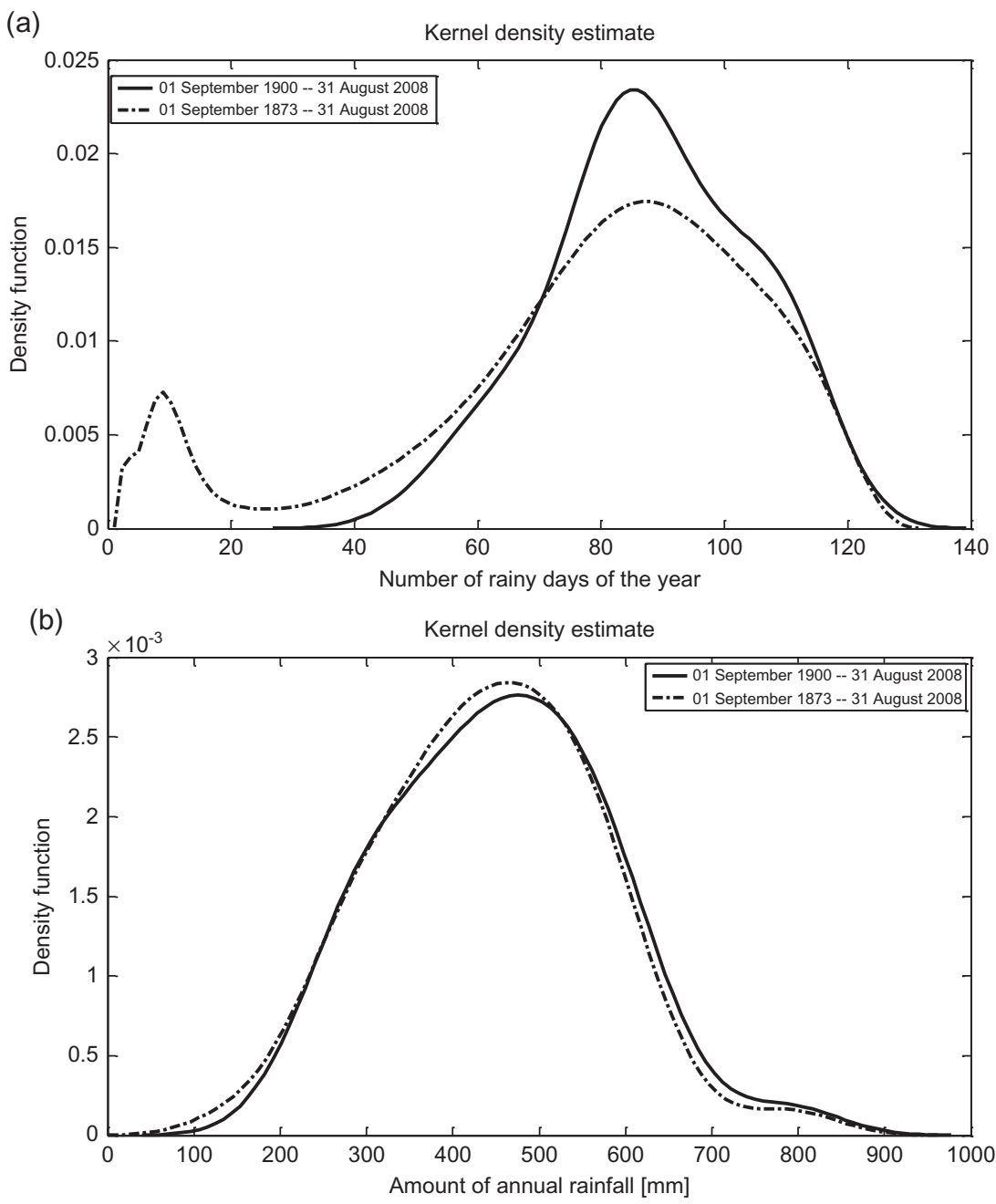

Fig. 4 Estimation of the kernel density of (a) the number of rain days and (b) precipitation amount of annual rainfall (solid line: 1 September 1873 to 31 August 2008, dashed line: 1 September 1900 to 31 August 2008). 
Table 4 Years and amount of rainfall related to subpopulation 2 .

\begin{tabular}{lll}
\hline Year & Number of rainy days & Annual rainfall $(\mathrm{mm})$ \\
\hline $1885 / 86$ & 3 & 152 \\
$1891 / 92$ & 9 & 593 \\
$1897 / 98$ & 9 & 440 \\
$1898 / 99$ & 11 & 345 \\
$1899 / 90$ & 12 & 525 \\
$1879 / 80$ & 22 & 143 \\
$1884 / 85$ & 27 & 427 \\
\hline
\end{tabular}

the years before 1900 the records of rainfall were not made daily, leading to an over-estimation of the number of rainless days, which actually corresponds to lack of data; or the number of rainy days during that period really was lower. In the first hypothesis, even if the records were not made once a day, this does not necessarily affect the precipitation accumulated on scales longer than a few days. Thus, studies of rainfall at scales longer than one week can be made using the data collected during the period before 1900 . The data collected between 1873 and 1900 were thus used only for the study of temporal scales exceeding one week.

In conclusion, the whole of these investigations underlines that the studied process admits a strong variability on all time scales $(5 \mathrm{~min}, 1 \mathrm{~d}, 1$ month and 1 year). This rainfall variability is strongly dominated by the variability of rainfall occurrence.

\section{METHODOLOGY}

Interpreting Fig. 2, we note an important agreement between rainfall amount and the number of rain days. Assuming that the temporal variability is mainly controlled by intermittency (the presence or absence of rainfall during a given time period), we try to characterize the rainfall structure by the fractal dimension of its occurrence. The fractal dimension of rain occurrence is calculated by using the method of box counting. Consider an object $A$ of fractal dimension $D_{f}$, included in a space of Euclidian dimension, $D$. If we perform a structure on a regular grid with mesh dimension $a$ (whether value $D$ is equal to 1,2 or 3 , the meshes are segments, squares or cubes) the number $N_{\lambda}(A)$ of meshes necessary to cover the fractal object $A$ is a function of $a$ (Hubert and Carbonnel 1989, Falconer 1990, Le Méhauté 1990, Hubert 1995):

$$
\log \left(N_{\lambda}(A)\right)=-D_{f} \log (a)+K
$$

where $K$ is a constant. According to this formulation, the fractal dimension is defined as being the opposite of the slope of linear regression of the number of boxes versus mesh size, in a bi-logarithmic plan. For rainfall time series, the space (time space) is of the dimension $D=1$ and the meshes will be segments of a straight line; the maximum value of the fractal dimension of rain occurrence will be equal to 1 (Hubert and Carbonnel 1989, Biaou 2004) $\left(0<D_{f}<1\right)$.

Two box-counting methods are suggested by Olsson et al. (1992). The first method takes a null threshold of rain detection (i.e. we consider the whole rain structure). In the second method, the rain occurrence is analysed at various intensity thresholds, and is called the functional box-counting method. It is a modified version of the box-counting method elaborated by Lovejoy et al. (1987) in the framework of the analysis of atmosphere stratification and cloud discontinuity. The mesh size is taken as successive powers of two.

Here, the study of rainfall occurrence through the analysis of the fractal dimension of the support of precipitation is performed using three different approaches: In Section 4, we apply the box-counting method to the series of all four rainfall stations, Tunis-Manoubia, Mornag, Soukra and Sidi Thabet, to estimate the dimension corresponding to the sensor detection threshold in a first step. The time step of the series is $5 \mathrm{~min}$. For the first size of the box $\left(2^{0}=1\right.$, that is, $1 \times 5=5 \mathrm{~min}$ ), we count the number of 5-min boxes containing rain. The second size of segments is $5 \times 2^{1}=10 \mathrm{~min}$; we count the number of 10 -min segments containing rain, and so on. We proceed this way for all the box sizes until we reach the box size $5 \mathrm{~min} \times 2^{n}$, which is equal to the total length of the series. Logarithmic plotting of the number of boxes according to their size shows linear zones expressing a zone of scale invariance for which the fractal dimension is determined (equation (1)). In a second step, we consider the evolution of scaling regimes and of the fractal dimension by changing the threshold of rain detection. In fact, the use of data without a threshold integrates the whole rainfall structure so that peaks due to convective rain are not separated from frontal rain. By increasing the threshold, the rainfall structure changes and the scaling regimes could be modified. Nevertheless, by using increasingly high thresholds, we erase part of the rainfall information (i.e. the frontal rain part).

In Section 5, we proceed as in Section 4, but working with the daily series of the Tunis-Manoubia station. We test the longest available sample as a power of two, which is about 90 years $\left(L=2^{15} \mathrm{~d}\right)$, to distinguish the breaks of gradient and calculate the 
corresponding fractal dimensions of rain occurrence. Note that the zero thresholds used for the analysis of the two resolutions of series are not equivalent. It is expressed in one case by an accumulation of $0.024 \mathrm{~mm}$ during $5 \mathrm{~min}$ and in the other case by a daily accumulation of $0.9 \mathrm{~mm}$.

In Section 6 we review the evolution of the fractal dimension of rain occurrence over various time windows. As a period of nearly a century is available for this study at a daily time step, the evolution of the fractal dimension is analysed across time and sub-time series of 22, 11 and 6 years' length. The goodness-of-fit $R^{2}$ and $95 \%$ confidence limit of the sampling distribution of the slope of the regression are estimated and tested.

\section{APPLICATION TO TIME SERIES WITH 5-MIN TIME STEP}

\subsection{With the sensor detection threshold}

The fractal dimension of rain occurrence at the four rainfall stations (Tunis-Manoubia, Mornag, Soukra and Sidi Thabet) was evaluated by adopting thresholds of zero when applying box counting. The start and end dates of the series are reported in Table 2. The lengths of the data series are around 2.5 years $\left(5 \times 2^{18}\right.$ min) for Tunis-Manoubia, Mornag and Sidi Thabet, and 1.25 years $\left(2^{17} \times 5 \mathrm{~min}\right)$ for Soukra (Table 3$)$. The results of 18 counts for each station for specific box sizes, the lengths of which are the terms of a geometric progression of term 1 and of reason 2 multiplied by $5 \mathrm{~min}$, are presented in Fig. 5 .
Figure 5 shows three scaling breaks for the four stations at points numbered 10, 12 and 16, representing boxes of size $2 \mathrm{~d}, 7 \mathrm{~d}$ and $113 \mathrm{~d}$. Thus, changes in gradient are detected based on four groups of aligned points. Temporal and spatial classifications of atmospheric outflow (Orlanski 1975, Pielke 1984) are used to interpret the regimes identified: The first regime of between $5 \mathrm{~min}$ and $1 \mathrm{~d}$ is typical of the micro-scale and characterizes the internal structure of rainfall events. The transition ( $1-7 \mathrm{~d}$ ) corresponds to meso-scale rainfall structures of spatial extent $20-200 \mathrm{~km}$, characteristic of frontal systems. The second regime of between $7 \mathrm{~d}$ and 8 months corresponds to the synoptic scales linked to the general circulation. The last alignment of points, 16 to 18 , corresponds to the saturation of the available space by rain and a fractal dimension equal to one, and reflects a behaviour highlighted by previous authors (cf. Table 1).

Only the length of the saturation period differs from one author to another in the reviewed literature (Table 1). It is in fact directly related to the length of the dry period. Due to the occurrence of a 4-month dry period in Mediterranean semi-arid areas, it is not surprising to observe a particular behaviour concerning the length of the saturation period. We obtained a beginning for the saturation period after $113 \mathrm{~d}$. Considering Table 1, Olsson (1993) used rainfall data collected at Lund (Sweden), Hubert and Carbonnel (1989) data obtained in Ouagadougou (Burkina Faso), Lavergnat and Golé (1998) data from Palaiseau (France), Schmitt et al. (1998) data from Uccle

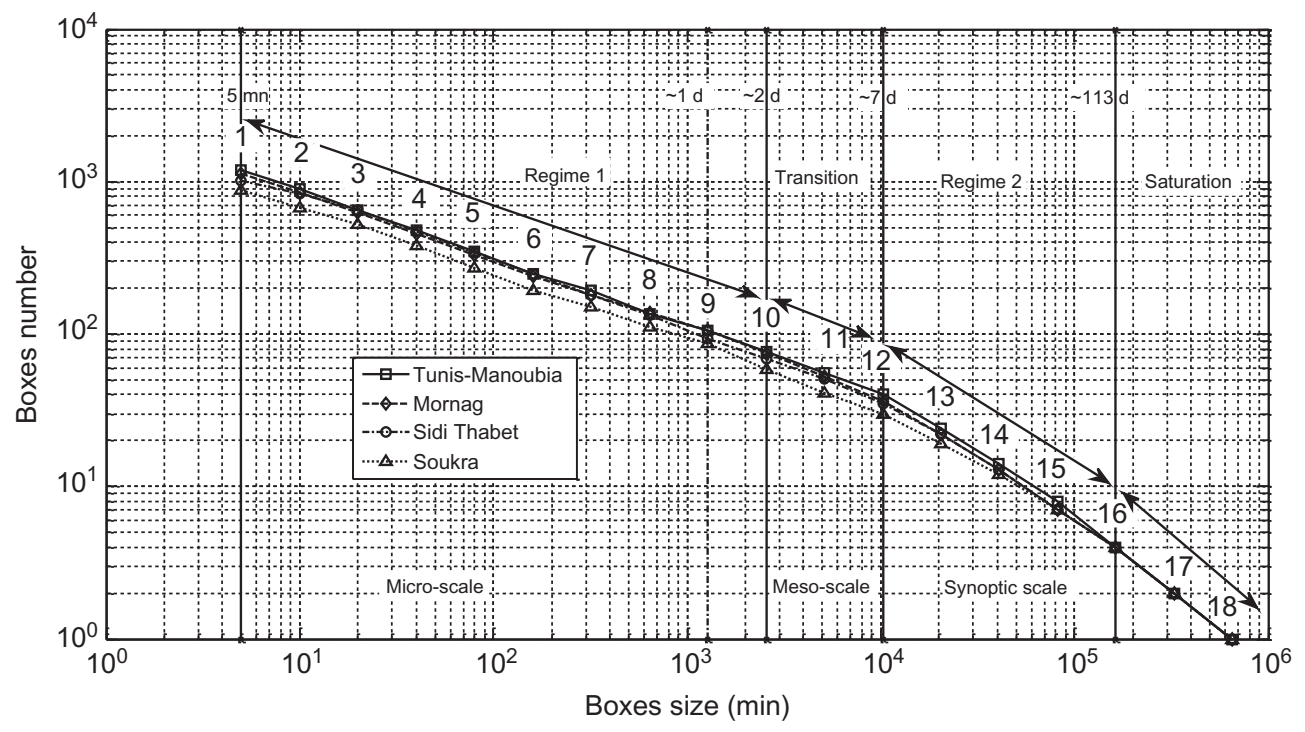

Fig. 5 Box counting for the Tunis-Manoubia, Mornag, Sidi Thabet and Soukra stations derived from 5-min rainfall series (series lengths $5 \times 2^{17} \mathrm{~min}$ ). 
(Belgium) and Veneziano and Iacobellis (2002) data collected at Florence (Italy), and in each case the scale break for saturation is observed to be a few days, respectively $7,21,7,3.5$ and $3.5 \mathrm{~d}$, which attests to the importance of the length of the saturation regime as well as the relative homogeneity of the rain support throughout the year. In other words, the length of the saturation period is very particular to the area considered. Therefore, contrary to studies performed in less contrasted climates (at least $10 \mathrm{~min}$ of rain for any 3.5-d period in Belgium or at least 1 min of rain for any 7-d period in Sweden), precipitation is not systematically observed over periods of a few days in our semi-arid case. Continuous rain events of $5 \mathrm{~min}$ or longer only occur during periods of $113 \mathrm{~d}$ length or longer.

Table 5 summarizes the characteristics of the first three groups identified in this study: the fractal dimension of the occurrence of rainfall, $D_{f}$; the constant, $K$ (equation (1)); and the coefficient of determination, $R^{2}$. We observe similar behaviour for the four series. Indeed, the first regime of scaling has a fractal dimension between 0.43 and 0.44 . The existence of several self-similar structures for the finer structure of rainfall is mentioned by many authors (Table 1 ). The $D_{f}$ obtained here $(0.44)$ is a little different to that of Schmitt et al. (1998) and de Lima and de Lima (2009) with a resolution of $10 \mathrm{~min}$, and also Verrier et al. (2011) with a resolution of $15 \mathrm{~s}$ who obtained a $D_{f}$ of 0.55 . Veneziano and Iacobellis (2002) found a $D_{f}$ of 0.5 for time increments ranging from $20 \mathrm{~min}$ to $3.5 \mathrm{~d}$ for a time series resolution of $20 \mathrm{~min}$. Hubert and Carbonnel (1989) obtained a $D_{f}$ of 0.22 for a

Table 5 Coefficient of linear regression, $K$, and coefficient of determination, $R^{2}$, obtained by applying equation (1) for the evaluation of the fractal dimension, $D_{f}$, of the four stations.

\begin{tabular}{lllll}
\hline & Station & $D_{f}$ & $K$ & $R^{2}$ \\
\hline Regime 1 & Tunis Manoubia & 0.44 & 7.80 & 0.999 \\
Alignment of points & Mornag & 0.43 & 7.72 & 0.999 \\
$\quad$ 1 to 10 & & & & \\
5 min to 2 d & Sidi Thabet & 0.44 & 7.74 & 0.997 \\
& Soukra & 0.43 & 7.51 & 0.999 \\
Transition & Tunis Manoubia & 0.46 & 7.97 & - \\
Alignment of points & Mornag & 0.53 & 8.48 & - \\
$\quad$ 10 to 12 & & & & \\
2 to 7 d & Sidi Thabet & 0.49 & 8.09 & - \\
& Soukra & 0.49 & 7.90 & - \\
Regime 2 & Tunis Manoubia & 0.82 & 11.33 & 0.996 \\
Alignment of points & Mornag & 0.80 & 11.00 & 0.998 \\
$\quad$ 12 to 16 & & & & \\
7 to 113 d & Sidi Thabet & 0.79 & 10.91 & 0.997 \\
& Soukra & 0.73 & 10.14 & 0.998 \\
\hline
\end{tabular}

scale ranging from $1 \mathrm{~h}$ to $32 \mathrm{~h}$ using an hourly series of only $170 \mathrm{~d}$ length. Lavergnat and Golé (1998) do not observe this regime, but used only four months of observations. The results of Olsson et al. (1992), who identify a break in scale at $45 \mathrm{~min}$, are not consistent with ours. These differences can be attributed either to the differences of rain structure (the previous studies do not concern the semi-arid Mediterranean climate), or to the differences of rainfall threshold detection of the gauges used. We should emphasize that the zero threshold used here is an arbitrary threshold related to sensor sensitivity and to its time resolution.

For the second regime, we obtain a $D_{f}$ of between 0.79 and 0.82 . The Soukra series is therefore too short to present a reliable description of this regime. We note that estimation of this dimension is very sensitive to the length of series used. The analysis of longer daily series, as in Section 5, is much better suited to the study of this regime characteristic of synoptic scales.

In the case of the transition zone (alignment of points 10 to 12) the scale ratios are too weak because $D_{f}$ is estimated with only three points and it is thus hard to judge the quality of the alignment. The $D_{f}$ are between 0.46 and 0.53 . This intermediate alignment is considered as a regime of transition between the first regime, which characterizes the micro-scale structure of the support, and the second regime which characterizes a big scale. However, we are cautious with such an interpretation due to the shortness of alignment of points 10 to 12 . Thus, Fig. 5 may also be interpreted as displaying a single regime (micro-scale) plus transition towards saturation, and saturation.

\subsection{Application of different thresholds of rain intensity}

The structure of rain supporting does not seem to be modified by a small increase of the detection threshold. The structures and gradients obtained in Fig. 6 are identical for thresholds $0,0.1$ and $0.2 \mathrm{~mm}$ per $5 \mathrm{~min}\left(\mathrm{~mm}^{-1} \mathrm{~min}^{-1}\right)$. For thresholds $\geq 0.3 \mathrm{~mm} 5 \mathrm{~min}^{-1}$ $\left(3.6 \mathrm{~mm} \mathrm{~h}^{-1}\right)$ the structure of the rainfall field changes and we observe a new break of $1 \mathrm{~h} 20 \mathrm{~min}$. Figure 7 shows the results of box counting for the Mornag station for thresholds $0,0.4$ and $1 \mathrm{~mm} 5 \mathrm{~min}^{-1}$. The $D_{f}$ of the regime corresponding to the box sizes from $5 \mathrm{~min}$ to $1 \mathrm{~h} 20 \mathrm{~min}(0.37)$ is higher than that of the regime ranging from $1 \mathrm{~h} 20 \mathrm{~min}$ to $2 \mathrm{~d}(0.24)$, but both are lower than that with a zero threshold (0.43). Likewise for the other observed regimes, the fractal dimension 


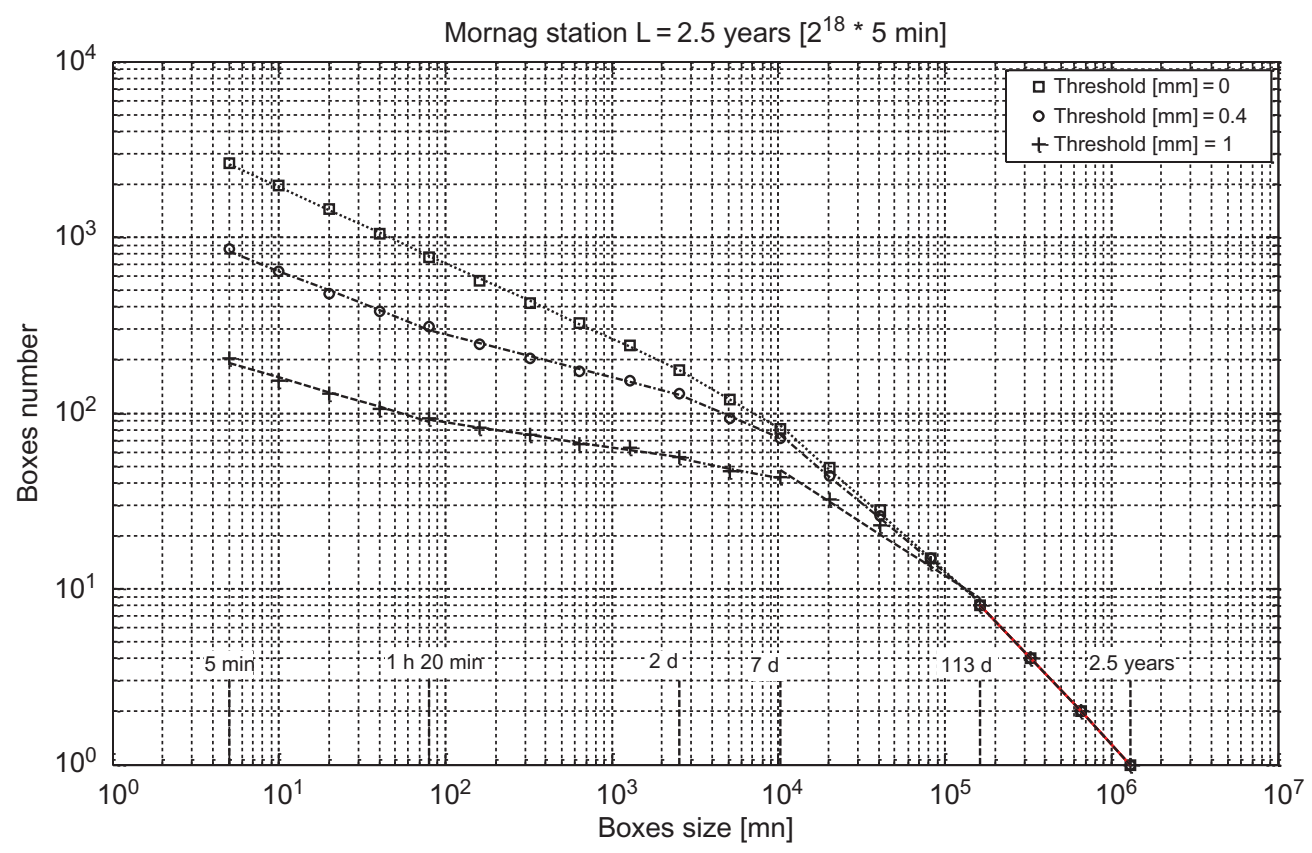

Fig. 6 Box counting result for the 2.5-year-long, 5-min rainfall series of Mornag station for rain intensities: 0, 0.4 and $1 \mathrm{~mm}$ per 5 min. Straight lines are linear regression adjustments.

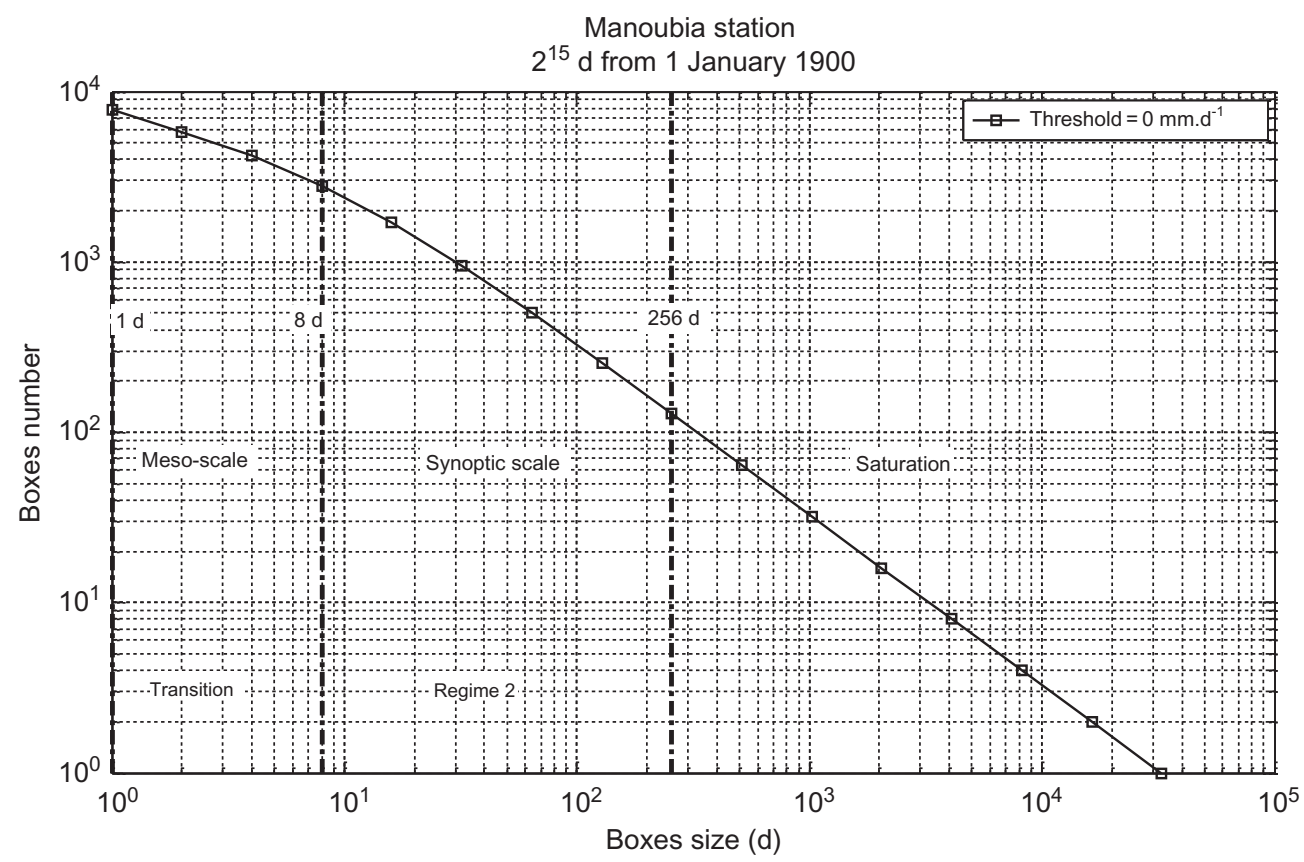

Fig. 7 Box counting derived from the daily rainfall series of Tunis-Manoubia station. The sample size is about 90 years $\left(2^{15} \mathrm{~d}\right)$.

decreases. The break observed at $1 \mathrm{~h} 20$ min persists for larger thresholds with a decrease in the fractal dimension. The curve patterns thus obtained are consistent with the work of Olsson $(1992,1993)$ in the case of series at 1-min resolution. However, Olsson observes a break of 45 min with much greater $D_{f}$ values.
This behaviour is interpreted as related to the features of the Mediterranean climate in the Tunis region. Intense precipitation occurs due to isolated convective cloud structures of large dimensions, having a lifetime of a few hours during which the events occur in a collective way. The increase of the threshold would "filter" out the frontal structure so as to 
keep only the convective structures. In fact, when higher thresholds of rainfall intensity are considered, the structure of convective events appears progressively. Convective structures present properties of scale invariance between $5 \mathrm{~min}$ and $1 \mathrm{~h} 20 \mathrm{~min}$. The low value of the $D_{f}$ of this regime can be interpreted as a high degree of irregularity in the distribution of the support of these structures.

\section{APPLICATION TO DAILY SERIES}

\subsection{With the sensor detection threshold}

The results of box counting and the fractal dimensions calculated for the daily series of the Tunis-Manoubia station are reported in Table 6 and Fig. 7. The series length is about 90 years (due to the reservations mentioned in Section 2 on data quality before 1900) and the series used here starts on 1 January 1900. The intensity threshold is zero.

In Fig. 7, we find breaks similar to those observed in the study performed with a 5-min resolution. The high $R^{2}$ values indicate the quality of the obtained alignments. The daily resolution does not allow observation of Regime 1 which characterizes small-scale structures. Again we find a zone of scale invariance corresponding to the scales between 1 and $8 \mathrm{~d}$ with a fractal dimension $D_{f}$ equal to 0.49 (transition scale), and also a zone of invariance that characterizes large scales varying from $8 \mathrm{~d}$ to $256 \mathrm{~d}$ with a fractal dimension of 0.89 (synoptic scale). The alignment of points 9 to 16 with a slope of -1 is evident, since, for a box of size $\geq 256 \mathrm{~d}$, we observe at least one rainy day, corresponding to the saturation of the available space by rain occurrence. Thus, the scale invariance zones are similar, with slightly different fractal dimensions, for the daily and 5-min resolution data. The difference is greatest for the synoptic scale, for which we found $D_{f}$ of 0.8 for 5 -min resolution data; however, we can deal only with a 2 -year series, which a priori allows less

Table 6 Coefficients of linear regression, $K$, and of determination, $R^{2}$, obtained by applying equation (1) for the evaluation of the fractal dimension, $D_{f}$, of the occurrence of daily rain at the Tunis-Manoubia station.

\begin{tabular}{lllll}
\hline Series start & Scale & $D_{f}$ & $K$ & $R^{2}$ \\
\hline $\begin{array}{l}\text { 1 January } \\
1900\end{array}$ & $\begin{array}{l}\text { Transition: alignment } \\
\text { of points 1 to 4, } \\
\text { 1-8 d } \\
\text { Regime 2: alignment } \\
\text { of points 4 to 9, } \\
\text { 8-256 d }\end{array}$ & 0.49 & 8.99 & 0.994 \\
& & & & \\
&
\end{tabular}

reliable estimation than that based on the longer daily series.

The observed regimes of scale invariance are fairly consistent with most results in the literature (Table 1). Indeed, these results reflect those obtained using daily series by Tessier et al. (1988, 1989) and Hubert and Carbonnel (1989) in terms of scaling breaks at around one week and 8 months (after which saturation), but not the Olsson et al. (1992) results, which identified the supporting saturation of rainfall at $10 \mathrm{~d}$. However, the $D_{f}$ values are not identical; we obtained 0.89 for the daily series, cf. 0.8 in Table 1.

The above interpretation of box-counting results may require caution. According to Schmitt et al. (1998) and Veneziano and Iacobellis (2002), only two scaling regimes should be considered, which would correspond in our work to the micro-scale regime and saturation part. Thus, the second regime, previously interpreted as synoptic scale, is instead interpreted as an extension of the transition to saturation. Thus, the high $D_{f}$ value of the synoptic scale results from an over-estimation, because it is affected by the tendency to saturation. The distinction between regimes and saturation effects was cited by de Lima and de Lima (2009) as a practical problem in applying the box-counting method.

\subsection{Application of different thresholds of rain intensity}

In the case of the daily series, increasing the threshold does not show further ruptures. Figure 8 shows the results of box counting for threshold intensities of 0,8 and $16 \mathrm{~mm} \mathrm{~d}^{-1}$. The regimes of scale invariance observed previously are not modified. For a threshold $>8 \mathrm{~mm} \mathrm{~d}^{-1}$, we observe a decrease of the $D_{f}$ of these regimes, and also a shift in the break towards larger increments of time. The synoptic regime is between 16 and $512 \mathrm{~d}$, instead of 8-256 d initially, and its fractal dimension decreases from 0.9 to 0.70 and 0.45 , respectively, for the 8 - and $16-\mathrm{mm} \mathrm{d}^{-1}$ thresholds. These modifications are easily explained: the increase of the threshold of rain occurrence detection naturally reduces the rain supporting and increases the duration of the dry period. The differences observed between the $D_{f}$ estimated at 0.8 for the 5 -min series and at 0.9 for the daily series are perhaps partly explained by the different detection thresholds. We can assume that a series of rainfall intensities measured with a more sensitive sensor will lead to a $D_{f}$ greater than 0.9 . The daily resolution does not allow the filtering out 


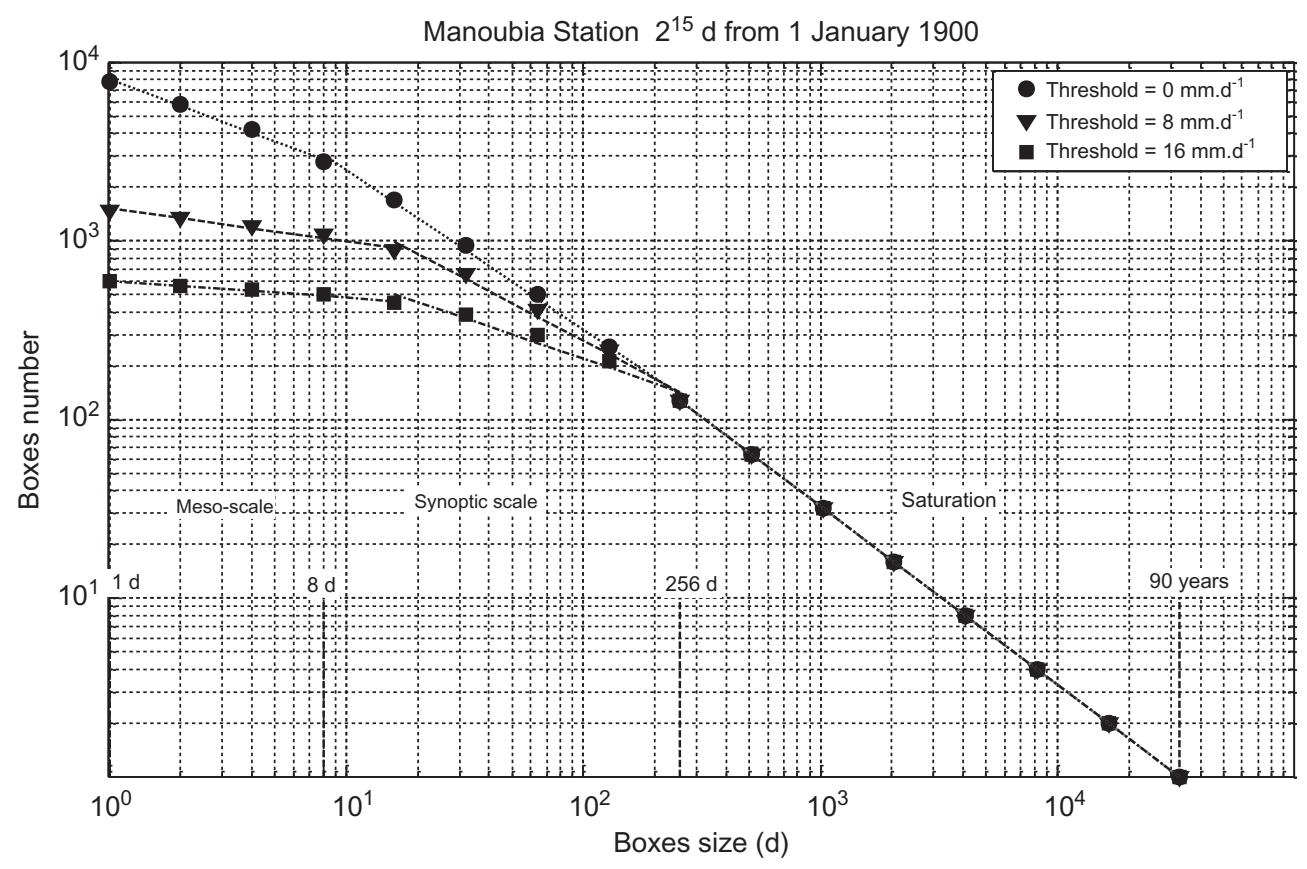

Fig. 8 Box counting using daily rainfall thresholds of 0,8 and $16 \mathrm{~mm}$ in calculation of fractal dimensions of rain occurrence for Tunis-Manoubia station.

of frontal structures from convective structures that can be separated only if the internal structure of the events is considered.

\section{TEMPORAL EVOLUTION OF THE FRACTAL DIMENSION}

Sub-time series are considered to study the temporal evolution of $D_{f}$. Because we deal with lengths equal to $2^{n}$ years, in order to obtain samples of a minimum number of realizations, sequences of $2^{13} \mathrm{~d} \approx 22$ years, $2^{12} \mathrm{~d} \approx 11$ years and $2^{11} \mathrm{~d} \approx 6$ years of length are considered. As the available times series is 136 years long, we have estimated the fractal dimension for 21 successive series of 6 years, nine successive series of 11 years, and five successive series of 22 years. The linear regression of the fractal dimension over time was then performed to analyse the trend over the last century.

Whatever the width of the window used, the same breaks as those obtained for the total series ( $8 \mathrm{~d}$ and 8 months) are observed; i.e. there is a stability to the previously described regimes. The linear regressions are reported in Fig. 9, which presents the evolution of $D_{f}$ of the transition regime corresponding to the mesoscale (1-8 d; top) and of the second regime (8-256 d; bottom) corresponding to synoptic scales. The vertical bars indicate intervals of confidence of $95 \%$ for the estimation of the slope $D_{f}$ using the $t$-test (Wilks
2006). The evolution of $D_{f}$ values is identical regardless of the size of the considered sequence $(6,11$ or 22 years).

For the synoptic scale, we note a slightly lower value of $D_{f}$ before 1930 compared to the following period, which is more stable. The null hypothesis of no change in slope is accepted at $5 \%$ for all sizes of series.

For the meso-scale regime, the goodness-of-fit values of the regressions for the 22-year $\left(R^{2}=\right.$ $0.73)$ and 11-year $\left(R^{2}=0.85\right)$ series are good, but poor for the 6-year series $\left(R^{2}=0.33\right)$. The null hypothesis of no change in regression slope is rejected at the $5 \%$ level of confidence for the series of length 11 years, but retained for the series of length 22 years.

To investigate the trend in $D_{f}$ series, we used the Mann Kendall test. Kendall (1975) described a normal approximation test that can be used for data sets with more than 10 values, provided there are few tied values within the data set. Since the sample size corresponding to sequences of length 22 years is $<10$, we apply the Mann-Kendall test only for the sequences of length 11 and 6 years. We performed the MannKendall test on the null hypothesis of trend absence against the alternative of trend. The null hypothesis of trend absence is rejected at the 5\% significance level for the meso-scale regime, which is the same conclusion as for the sampling distribution $t$-test of the regression slope in the case of sequences of length 

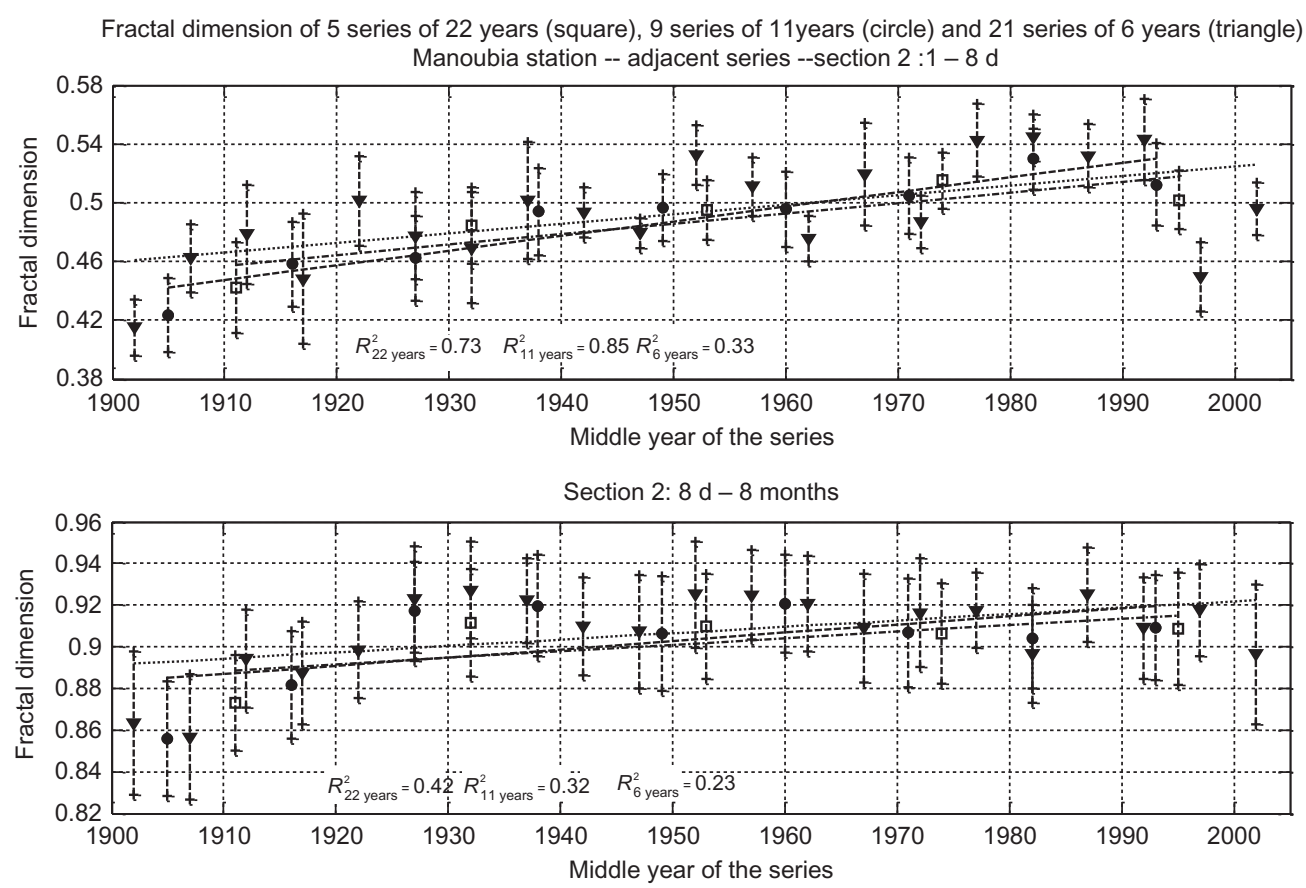

Fig. 9 Evolution with time of the fractal dimensions of precipitation support for: (a) the 1-8 d regime, and (b) the 8 d- 8 month regime. $\mathbf{\nabla}$ : 21 series of 6 years, $\bullet$ : 9 series of 11 years, and $\square$ : five series of 22 years. The vertical bars are $95 \%$ confidence intervals for the estimation of $D_{f}$ using the $t$ test.

11 years. However, the Mann-Kendall test indicates the absence of trend at the $5 \%$ level for the synoptic scale regime for series of 6 and 11 years.

It is worth noting that an increase of $D_{f}$ signifies an increase of rain occurrence, which presents an interesting direction for research.

\section{CONCLUSION}

Analysis of the box-counting plots of four series of rainfall observations with a sampling time of $5 \mathrm{~min}$ has clearly shown that rainfall presents properties of scale in a mono-fractal framework. A first regime, characteristic of the micro-scale that describes the internal structure of rainfall events and concerns time scales between $5 \mathrm{~min}$ and $1 \mathrm{~d}$, is identified. A second regime between $7 \mathrm{~d}$ and 8 months that corresponds to the synoptic scale may also be distinguished. The final regime corresponds to saturation of the available space by rain. A transition at $1-8 \mathrm{~d}$ is outlined and corresponds to meso-scale rainfall structures.

For the first rainfall regime, a fractal dimension of 0.44 was obtained. This micro-scale behaviour is mentioned by several authors, but with a larger fractal dimension, around 0.55 , for oceanic and subtropical locations, cf. the semi-arid focus of our studies. The analysis performed with different thresholds on the 5-min series showed a break near $1 \mathrm{~h} 20$ min that can be interpreted as another scaling regime characteristic of convective situations. The convective part of the rain process appears progressively when the threshold of rainfall intensity is increased. The 5-min resolution of the available data is not sufficient to allow analysis on an event basis to distinguish the structure of convective events from those of frontal systems; higher-resolution data are necessary to refine the analysis of the micro structure of rain (e.g. disdrometer data).

Analysis of the box-counting plots of a daily time series also shows that the rainfall regime characteristic of synoptic scales ranges from $7 \mathrm{~d}$ to 8 months and has an auto-similar structure, of which the fractal dimension is around 0.9. The latter is affected by the saturation regime which comes immediately after.

The feature that distinguishes our study area is the saturation period. We obtain a beginning for the saturation period after 8 months, whereas other authors observe saturation after a few days. The saturation of the available space by rain occurrence is a consequence of the great length of the dry period. This result highlights a feature of rainfall of the semiarid Mediterranean climate - prolonged dry periods with rare, isolated rain events.

Despite some reservations, the length of the available daily time series gives us the opportunity to study possible changes during the last century of 
the fractal dimension of time intervals corresponding to meso-scale and synoptic scales. Unlike the fractal dimension at synoptic scale that is relatively stable, the fractal dimension at meso-scale steadily increased during the 20th century. This trend is statistically significant at the $5 \%$ level of confidence using the $t$ test of regression slope as well as the Mann-Kendall test.

Acknowledgements The authors would like to thank the General Directorate of Water Resources (DGRE, Tunisia). This project is financed by the Tunisian-French scientific cooperation Project CMCU: Estimation and mapping of extreme rainy events of the Tunis area (Code 10G1102), 2010-2012.

\section{REFERENCES}

Bara, M., et al., 2009. Estimation of IDF curves of extreme rainfall by simple scaling in Slovakia. Contributions to Geophysics and Geodesy, 39/3, 187-206.

Bendjoudi, H., et al., 1997. Interprétation multifractale des courbes intensité-durée-fréquence des précipitations. Comptes Rendus de l'Académie des Sciences - Series IIA - Earth and Planetary Science. Paris, 325, 323-326.

Biaou, C., 2004. De la méso-échelle à la micro-échelle : Désagrégation spatio-temporelle multifractale des precipitations. Thèse de doctorat, Ecole de Mines de Paris, France.

Castro, J., Cârsteanu, A.A., and Flores, C., 2004. Intensity-durationarea-frequency functions for precipitation in a multifractal framework. Physica A, 338 (1-2), 206-210.

de Lima, M.I.P. and de Lima, J.L.M.P., 2009. Investigating the multifractality of point precipitation in the Madeira archipelago. Nonlinear Processes in Geophysics, 16, 299-311.

De Michele, C., Kottegoda, N.T, and Rosso R., 2002. IDAF (intensity-duration-area-frequency) curves of extreme storm rainfall: a scaling approach. Water Science and Technology, 45 (2), 83-90.

De Michele, C., et al., 2011. Analytical derivation of rain intensityduration-area-frequency relationships from event maxima. Journal of Hydrology, 399 (3-4), 385-393.

De Montera, L., et al., 2009. The effect of rain-no rain intermittency on the estimation of the universal multifractals model parameters. Journal of Hydrometeorology, 10, 493-506.

Falconer, K., 1990. Fractal geometry: Mathematical foundations and applications. Chichester: John Wiley and Sons Ltd.

Friggit, F., Hubert, P., and Carbonnel, J.P., 1991. Caractérisation fractale de la succession des jours pluvieux au Burkina Faso. In: AUPELF-UREF. Utlilisation rationelle de l"eau des petits bassins versants en zone aride. Paris: John Libbey Eurotext, 43-49.

Gupta, V.K. and Waymire, E.C., 1993. A statistical analysis of mesoscale rainfall as a random cascade. Journal of Applied Meteorology, 32, 251-267.

Hubert, P., 1995. Fractals et multifractals appliqués à l'étude de la variabilité temporelle des précipitations In: R.A. Feddes, ed. Space and time scale variability and interdependencies in hydrological processes. Cambridge: Cambridge University Press, 175-181.
Hubert, P., 2005. La prédétermination des crues. Comptes Rendus de l'Académie des Sciences - Géoscience, 337, 219-227.

Hubert, P. and Carbonnel, J.P., 1989. Dimensions fractales de l'occurrance de pluie en climat soudano-sahélien. Hydrologie Continenentale, 4 (1), 3-10.

Hubert, P., Friggit, F., and Carbonnel, J.P., 1995. Multifractal structure of rainfall occurrence in West Africa. In: Z.W. Kundzewicz, ed. New uncertainty concepts in hydrology and water resources. Cambridge: Cambridge University Press, 109-113.

Isnard, H., 1950. La répartition saisonnière des pluies en Algérie. Annales de Géographie, 59 (317), 354-361.

Isnard, H., 1952. La répartition saisonnière des pluies en Tunisie. Annales de Géographie, 61 (327), 357-362.

Kendall, M.G., 1975. Rank correlation methods. 4th ed. London: Charles Griffin.

Langousis, A. and Veneziano, D., 2006. Intensity-duration-frequency curves from scaling representations of rainfall. Water Resources Research, 43, 1-12.

Langousis, A., et al., 2009. Multifractal rainfall extremes: theoretical analysis and practical estimation. Chaos, Solutions, and Fractals, 39 (3), 1182-1194.

Lavergnat, J. and Golé, P., 1998. A stochastic raindrop time distribution model. Journal of Applied Meteorology, 37, 805-818.

Le Méhauté, A., 1990. Les géométries fractales. Paris: Hermès.

Lovejoy, S., 1981. Analysis of rain areas in terms of fractals. In: 20th Conference on radar meteorology, November 30-December 3. Boston, MA: American Meteorological Society, 476-484.

Lovejoy, S., 1982. The area-perimeter relations for rain and cloud areas. Science, 216, 185-187.

Lovejoy, S., Schertzer, D., and Tsonis, A.A., 1987. Functional boxcounting and multiple elliptical dimensions of rain. Science, 235 (4792), 1036-1038.

M'Biandoun, M., Guibert, H., and Olina, J.P., 2002. Caractérisation du climat dans quatre terroirs de la zone soudano-sahélienne au Nord-Cameroun et conséquences pour l'agriculture. In: Actes du colloque, 27-31 mai 2002, Garoua, Cameroun.

Mandelbrot, B., 1975. Les objets fractals, forme, hasard et dimensions. Paris: Flammarion.

Mandelbrot, B., 1982. The fractal geometry of nature. San Francisco, CA: W.H. Freeman.

Menabde, M., et al., 1999. Multiaffine random field model of rainfall. Water Resources Research, 35 (2), 509-514.

Olsson, J., Niemczynowicz, J., and Berndtsson, R., 1993. Fractal analysis of high-resolution rainfall time series. Journal of Geophysical Research, 98 (D12), 23265-23274.

Olsson, J., et al., 1992. An analysis of the rainfall time structure by box counting - some practical implications. Journal of Hydrology, 137, 261-277.

Orlanski, I., 1975. A rational subdivision of scales for atmospheric processes. Bulletin of the American Meteorological Society, 56 (5), 527-530.

PANA (Programmes d'Action Nationaux pour l'Adaptation), 2003. Synthèse des études de vulnérabilité et d'adaptation aux changements climatiques:étude de cas du Burkina Faso. Atelier de formation sur les Programmes d'Action Nationaux pour l'Adaptation, Ouagadougou, Burkina Faso 28-31 octobre 2003 [online]. Available from: http://www.napa-pana.org/ files/workshops/burkina/12_Some_Etude_de_cas_Burkina.pdf [Accessed 28 May 2011].

Pielke, R.A. Sr, 1984. Mesoscale meteorological modeling. New York: Academic Press.

Schertzer, D. and Lovejoy, S., 1987. Physically based rain and cloud modeling by anisotropic, multiplicative turbulent cascades. Journal of Geophysical Research, 92, 9692-9714.

Schertzer, D. and Lovejoy, S., 2006. Multifractals en turbulence et géophysique. In: J.P. Kahane, ed. Iruption des géométries fractals dans les sciences. France: Académie Européene Interdisciplinaire des Sciences, 189-209. 
Schertzer,D., et al., 2006. Extrêmes et multifractals en hydrologie : résultats, validations et perspectives. La Houille Blanche, 5, $112-119$.

Schmitt, F., Vannitsem, S., and Barbosa, A., 1998. Modeling of rainfall time series using two-state renewal processes and multifractals. Journal of Geophysical Research, 103 (D18), 23,181-23,193.

Silverman, B.W., 1998. Density estimation for statistics and data analysis. Boca Raton, FL: Chapman \& Hall/CRC.

Tessier, Y., Lovejoy, S., and Schertzer, D., 1988. Multifractal analysis of global rainfall from 1 day to 1 year. $I n$ : D. Schertzer and S. Lovejoy, eds. Non linear variability in geophysics-scaling and fractals. Dordrecht: Kluwer, 2.

Tessier, Y., Lovejoy, S., and Schertzer, D., 1989. Multifractal analysis of global rainfall from 1 day to 1 year. Paper at European Geophysical Society XIV General Assembly, Barcelona.
Tessier, Y., Lovejoy, S., and Shertzer, D., 1993. Universal multifractals in rain and clouds: theory and observations. Journal of Applied Meteorology, 32, 223-250.

Veneziano, D. and Iacobellis, V., 2002. Multiscaling pulse representation of temporal rainfall. Water Resources Research, 38 (8), 13.

Verrier, S., Mallet, C., and Barthès, L., 2011. Multiscaling properties of rain in the time domain, taking into account rain support biases. Journal of Geophysical Research: Atmospheres, 116 (D20), doi:10.1029/2011JD015719.

Verrier, S., et al., 2010. Multifractal analysis of African monsoon rain fields, taking into account the zero rain-rate problem. Journal of Hydrology, 389 (1-2), 111-120.

Wilks, D.S., 2006. Statistical methods in the atmospheric sciences. Waltham, MA: Academic Press, International Geophysics Series vol. 91. 